\title{
User Interfaces
}

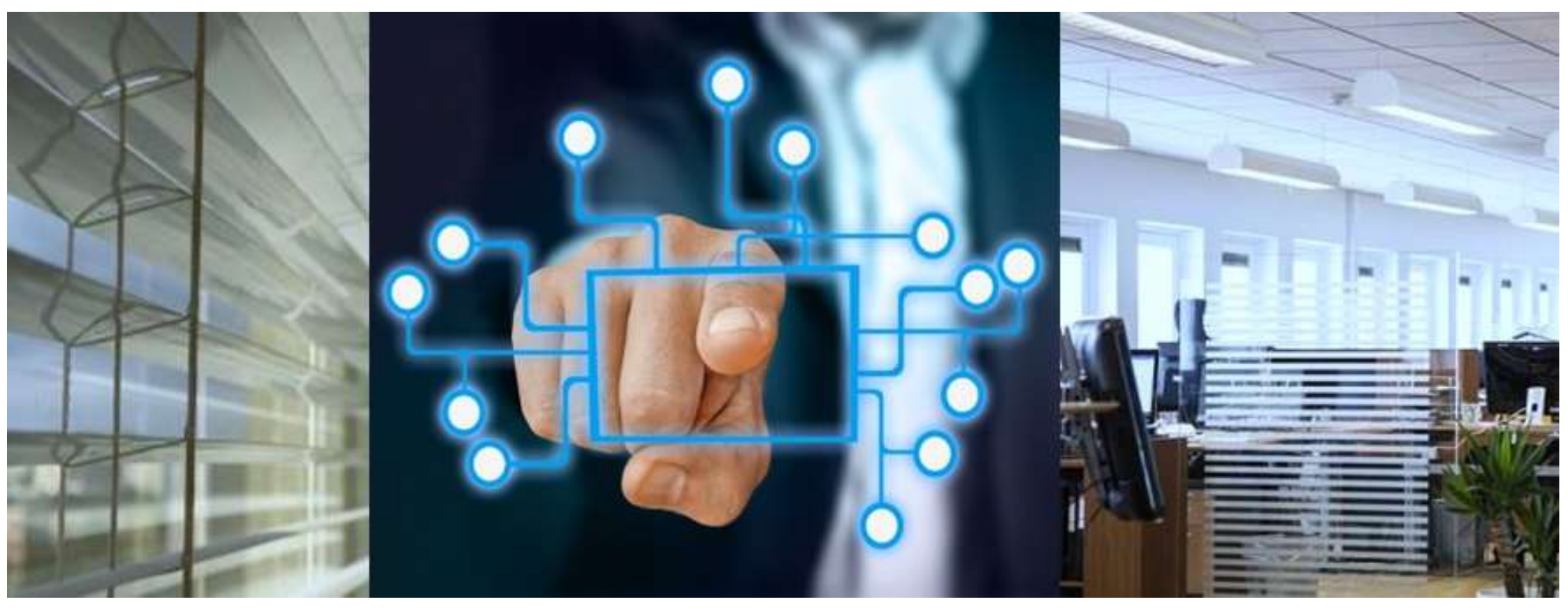

IEA SHC Task 61 / EBC Annex 77: Integrated Solutions for Daylighting and Electric Lighting 


\section{IEA Solar Heating and Cooling Technology Collaboration Programme (IEA SHC)}

The Solar Heating and Cooling Technology Collaboration Programme was founded in 1977 as one of the first multilateral technology initiatives ("Implementing Agreements") of the International Energy Agency. Its mission is "To enhance collective knowledge and application of solar heating and cooling through international collaboration to reach the goal set in the vision of solar thermal energy meeting $50 \%$ of low temperature heating and cooling demand by 2050."

The members of the IEA SHC collaborate on projects (referred to as Tasks) in the field of research, development, demonstration (RD\&D), and test methods for solar thermal energy and solar buildings.

Research topics and the associated Tasks in parenthesis include:

- Solar Space Heating and Water Heating (Tasks 14, 19, 26, 44, 54)

- Solar Cooling (Tasks 25, 38, 48, 53, 65)

- Solar Heat for Industrial or Agricultural Processes (Tasks 29, 33, 49, 62, 64)

- Solar District Heating (Tasks 7, 45, 55)

- Solar Buildings/Architecture/Urban Planning

(Tasks 8, 11, 12, 13, 20, 22, 23, 28, 37, 40, 41, 47, 51, 52, 56, 59, 63)

- Solar Thermal \& PV (Tasks 16, 35, 60)

- Daylighting/Lighting (Tasks 21, 31, 50, 61)

- Materials/Components for Solar Heating and Cooling (Tasks 2, 3, 6, 10, 18, 27, 39)

- Standards, Certification, and Test Methods (Tasks 14, 24, 34, 43, 57)

- Resource Assessment (Tasks 1, 4, 5, 9, 17, 36, 46)

- Storage of Solar Heat (Tasks 7, 32, 42, 58)

In addition to our Task work, other activities of the IEA SHC include our:

$>$ International Conference on Solar Heating and Cooling for Buildings and Industry

$>$ SHC Solar Academy

$>$ Solar Heat Worldwide annual statics report

$>$ Collaboration with solar thermal trade associations

\section{Country Members}

$\begin{array}{lll}\text { Australia } & \text { France } & \text { South Africa } \\ \text { Austria } & \text { Germany } & \text { Spain } \\ \text { Belgium } & \text { Italy } & \text { Sweden } \\ \text { Canada } & \text { Netherlands } & \text { Switzerland } \\ \text { China } & \text { Norway } & \text { Turkey } \\ \text { Denmark } & \text { Portugal } & \text { United Kingdom } \\ \text { European Commission } & \text { Slovakia } & \end{array}$

\section{Sponsor Members}

European Copper Institute International Solar Energy Society CCREEE EACREEE

ECREEE

RCREEE

RCREEE

SACREEE

For more information on the IEA SHC work, including many free publications, please visit www.iea-shc.org. 


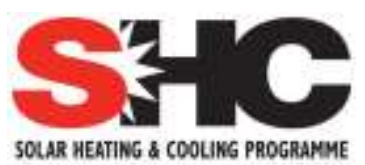

INTERNATIONAL ENERGY AGENCY

\section{User Interfaces}

\section{Editor: Marc Fontoynont}

Authors (in alphabetical order):

Bruno Bueno Unzeta, Jan de Boer, Ruben Delvaeye, Nikodem Dernegowski, Bertrand Deroisy, Marc Fontoynont, Bruce Norman, Daniel Neves Pimenta

\section{1-02-17}

DOI: 10.18777/ieashc-task61-2021-0004

\section{T61.B.4, A Technical Report of Subtask B}

The contents of this report do not necessarily reflect the viewpoints or policies of the International Energy Agency (IEA) or its member countries, the IEA Solar Heating and Cooling Technology Collaboration Programme (SHC TCP) members or the participating researchers.

Cover image left: (C) Pixabay 
AUTHORS (in alphabetical order)

Bruno BUENO UNZETA

Fraunhofer Institute for Solar Energy Systems ISE

Heidenhofstr. 2,

79110 Freiburg i. Br.

Germany

bruno.bueno@ise.fraunhofer.de

\section{Jan DE BOER}

Fraunhofer Institute for Building Physics IBP

Nobelstr. 12,

70569 Stuttgart

Germany

jan.deboer@ibp.fraunhofer.de

\section{Ruben DELVAEYE}

Belgian Building Research Institute (BBRI)

Avenue Pierre Holoffe, 21,

1342 Limelette

Belgium

ruben.delvaeye@bbri.be

Nikodem DERENGOWSKI

BUILD - Institut for Byggeri, By og Miljø

A.C. Meyers Vænge 15,

2450 København SV

Denmark

Bertrand DEROISY

Belgian Building Research Institute

Avenue Pierre Holoffe, 21,

1342 Limelette

Belgium

bertrand.deroisy@bbri.be
Marc FONTOYNONT

BUILD - Institut for Byggeri, By og Miljø

A.C. Meyers Vænge 15,

2450 København SV

Denmark

mfo@build.aau.dk

Bruce Nordman

Lawrence Berkeley National Laboratory

Berkeley, California, U.S.A.

BNordman@LBL.gov

Daniel NEVES PIMENTA

Fraunhofer Institute for Building Physics IBP Nobelstr. 12,

70569 Stuttgart

Germany

daniel.neves.pimenta@ibp.fraunhofer.de 


\section{KEYWORDS}

user interfaces, controls, lighting, shading, UX

\section{ACKNOWLEDGEMENTS}

The authors thank their respective funding agencies for supporting their work:

Denmark: ELFORSK (Contract EUDP 64017-05110)

We want to thank Bruce Nordman from LBNL, California USA for his major contribution to this document. LBNL is associated to IEA-SHC Task 61 / EBC Annex 77. Bruce Nordman has co-authored, together with the California Lighting Technology Center the report "Lighting User Interface Standard" through a PIER program of the

California Energy Commission (2010). The report is available at http://nordman.lbl.gov/lightui. Also at that URL is a pointer to proposed content for a standard for lighting control user interface elements, along with an appendix with discussion explaining considerations and decisions made in the course of developing the proposed content. 


\section{PREFACE}

Lighting accounts for approximately $15 \%$ of the global electric energy consumption and $5 \%$ of greenhouse gas emissions. Growing economies, higher user demands for quality lighting and rebound effects as a result of low priced and more versatile electric lighting continuously still lead to an absolute increase of lighting energy consumption. More light is used, often less consciously.

Especially the electric lighting market but as well the façade, daylighting und building automation sectors have seen significant technological developments in the past decade. However these sectors still act mainly independent of each other, leaving out big potentials lying in a better technology and market integration. This integration is on the one hand beneficial to providing better user-centred lighting of indoor spaces. On the other hand it can contribute significantly to the reduction of worldwide electricity consumptions and C02-emissions, which is in line with several different governmental energy efficiency and sustainability targets.

IEA SHC Task 61 / EBC Annex 77 "Integrated Solutions for daylighting and electric lighting - From Component to system efficiency" therefore pursues the goal to support and foster the better integration of electric lighting and daylighting systems including lighting controls with a main focus on the non-residential sector. This includes the following activities:

- Review relation between user perspective (needs/acceptance) and energy in the emerging age of "smart and connected lighting" for a relevant repertory of buildings.

- Consolidate findings in use cases and "personas" reflecting the behaviour of typical users.

- Based on a review of specifications concerning lighting quality, non-visual effects as well as ease of design, installation and use, provision of recommendations for energy regulations and building performance certificates.

- Assess and increase robustness of integrated daylight and electric lighting approaches technically, ecologically and economically.

- Demonstrate and verify or reject concepts in lab studies and real use cases based on performance validation protocols.

- Develop integral photometric, user comfort and energy rating models (spectral, hourly) as prenormative work linked to relevant bodies: CIE, CEN, ISO. Initialize standardization.

- Provide decision and design guidelines incorporating virtual reality sessions. Integrate approaches into wide spread lighting design software.

- Combine competencies: Bring companies from electric lighting and façade together in workshops and specific projects. Hereby support allocation of added value of integrated solutions in the market.

To achieve this goal, the work plan of IEA SHC Task 61 / EBC Annex 77 is organized according to the following four main subtasks, which are interconnected by a joint working group:

- Subtask A:

User perspective and requirements

- Subtask B:

- Subtask C:

- Subtask D:

- Joint Working Group: Evaluation tool \& VR Decision Guide

Subtask B focuses on the evolution of the technologies and identifies new opportunities offered by controls systems for lighting and daylighting systems, with the objective to improve energy performance as well as improving operation by occupants and facility managers. 


\section{EXECUTIVE SUMMARY}

This report shows; that the impact of a good User Interfaces (UI) is not only affecting the usability and comfort for the user, but is also a major key to save energy. At least as important for effectiveness to the quality of individual interfaces is consistency in the meaning of individual user interface elements (visual, conceptual, auditory, etc.)

How can User Interfaces help to save energy? In terms of energy saving, a good UI makes all the difference for the user by raising the awareness and by bringing transparency for the management of energy flows. A good UI is accomplished through the quality of its design, along with the UI elements being drawn from a common pool that matches user past experience and expectations

The system's User Interface (UI) needs to be easy and intuitive, so users actually know how to use it, and appreciate its effectiveness. If the goal is to reduce energy use, it needs to be comfortable for the user in an easily accessible way. In order for it to be comprehensible, the Ul elements need to be familiar.

The energy management can be hidden and embedded. When the UI is not fully intuitive, it is a key element to train the user in optimizing the system, in an attractive way. Understanding of the operation will allow the occupant to understand and interact in a way, an important contribution to reduce the energy consumption of the building.

Beginning with the basic categories of Lighting Interfaces (analog, digital and hybrid), and going through the several functions to more complex and self-learning solutions, this report gives a basic understanding of lighting and shading control interfaces. With this it gives an overview of the current trends and solutions on the market for professionals as well as nonprofessionals.

Among the most significant trends which have been identified are:

- The ability to customize the UI to the users' needs

- To synchronize with the global building management system

- To propose (or suggest) attractive pre-programmed options

- Too develop interfaces which are "educating" the user: making him or her understand the consequence of his (her) choices.

- Use of standard UI elements to facilitate basic user comprehension of the interface

Similar to a look through the keyhole it opens the view for new concepts and solutions to come of how people interact with lighting. 


\section{Contents}

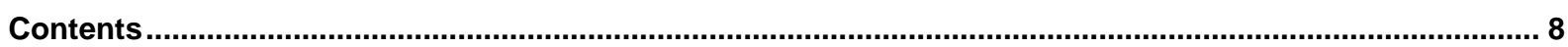

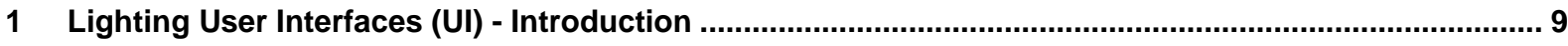

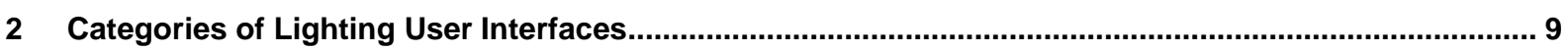

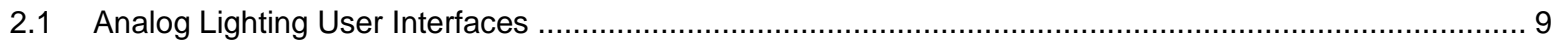

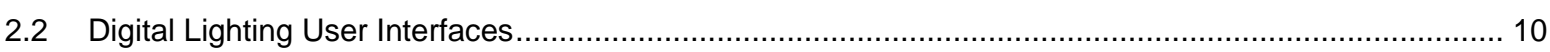

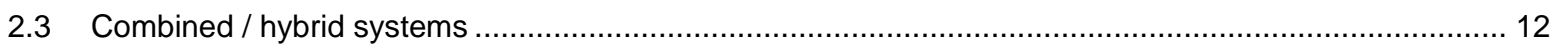

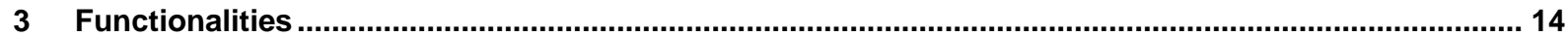

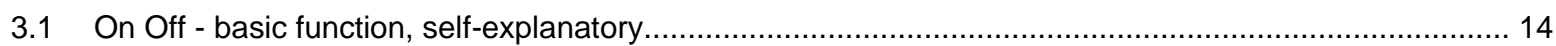

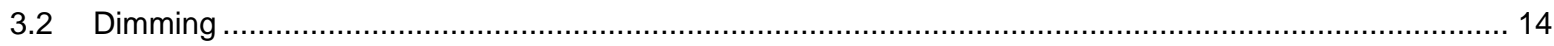

3.3 Tunable White - controlling the Corelated Colour Temperature of lighting. ........................................... 15

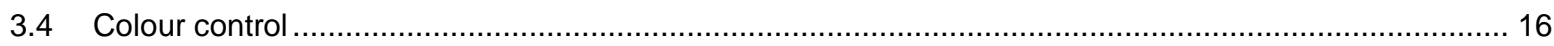

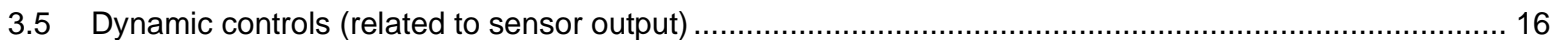

3.6 Creation of global luminous scenes

Error! Bookmark not defined.

3.7 Interfaces for control of shades, blinds, curtains and shutters ............................................... 18

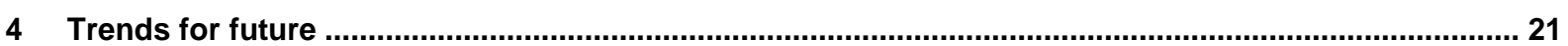

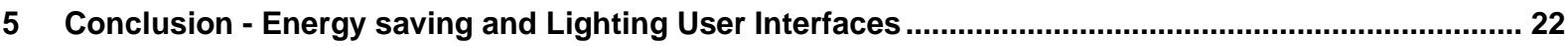

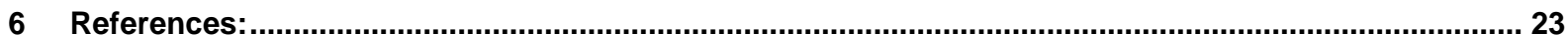




\section{Lighting User Interfaces (UI) - Introduction}

With the growth of technology, applications, and IOT (Internet of Things), the way of interacting with lighting is dynamically changing, and has been developing rapidly especially in the last decade. In the beginning, a simple switch was all that was needed to control the light in a room or a zone - just on and off.

Over time the lighting control 'menu' has grown and various options have been progressively added, such as dimming, colour change (with the rapid rise of RGB LEDs), sensor-based controls, zoning etc. While designing User Interface Systems (UI), the manufacturers are usually relying on their in-house designers and "common sense" practices, which results in multiple options available on the market, with no actual standardization of the design: both the individual element, but also the overall interface.

This report describes the whole arrange of possibilities. It proposes terms to describe the supply, classification of systems, and a critical analysis of the solutions, and opportunities they offer with respect to lighting, daylighting, energy savings and improved satisfaction by occupants and facility managers.

\section{Categories of Lighting User Interfaces}

Three main categories of user interface can be distinguished - analog, digital (screen based), and combined systems (with elements from both of the two).

Further classification can also be based (Nordman et al., 2017) on the mobility of the device - there are static, fixed control devices (switch on the wall, a tablet fixed to the wall), semi-portable devices that are movable, but usually are connected to the system with a wire, and finally there are fully portable devices, such as remote controllers in the analog systems, and smartphones in the digital systems.

\subsection{Analog Lighting User Interfaces}

Analog user interfaces are conventional and standard in lighting. The operation is based on manual interaction of the user with the system through switches, buttons, knobs and sliders. Analog systems have to be well thoughtthrough before release, as once installed they cannot be easily adjusted. A big advantage of analog systems is, that they are quite reliable due to their simplicity. Moreover, for many users, the physical act and tactile sensation of the interaction with control device is important, and gives a sense of reassuring feedback. It also allows to quickly judge the operation status of the device without looking at it. Hence many users still prefer analog controls over screen-based digital equivalents.

A well-designed analog user interface system must be intuitive and does not require much learning. Usually, to make the system aesthetically pleasing, the controls do not have labels or icons and require initial "trying-out" period to quickly learn the functionality. However, there are systems where small icons, or in some cases little descriptive labels, are implemented to show what they are controlling (e.g. parameters described in this document, or if there are multiple on/off switches, they can be named with zones of the room such as "general lighting", "wall lighting" etc.).

An essential aspect of these and any user interface is consistency across controls in individual elements. Simple analog switches show this issue, as with some countries not using the most basic of design principles, such as that "more" should be communicated with up, right, clockwise, and away. Some countries use the reverse convention, and others use a combination of the two. The other largest category of UI elements is graphical symbols, but colors, sound, and dynamic conditions also apply.

In terms of setup, analog systems do not require any major setup from the user, except from learning what each button/knob/slider does.

As it goes for location of the controls, most mechanical analog devices are placed on the wall right up on entering the space. This positioning also communicates the functionality to the user and makes it natural to assume that it is for lighting of the zone the user is entering. 


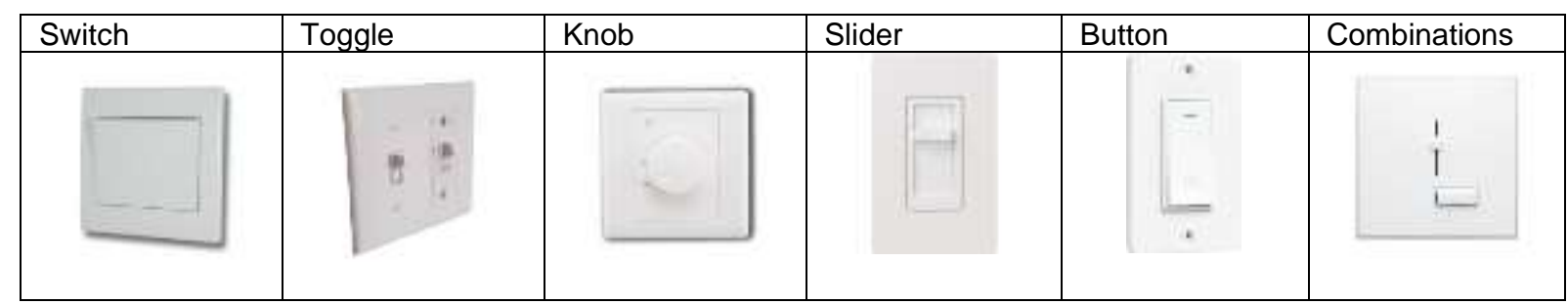

Figure 1. Examples of analog User Interface control devices. ${ }^{1}$

\section{Functionality - types of interaction:}

In the analogue system we can differentiate following control mechanisms based on the tactile interaction that the user performs:

- $\quad$ Pressing buttons, toggles or switches - in example, on/off button

- $\quad$ Turning a knob - a rotary control mechanism to adjust a parameter that has a given range; usually found in dimmers. Typically, a turn to right means "more" and left "less".

- $\quad$ Moving a slider - again, used to control a range within a parameter. Usually found in dimmers, or in modern lighting systems to control the colour temperature or RGB values (HUE sliders). Typically, moving slider to the right, or up means 'more', and this usage is consistent with the relevant international standard'.

- Hold - holding a pressed button - less intuitive then a slider, however can be easily implemented in the same device (one button with two functionalities), therefore simplifies the design and saves space. Holding a pressed button usually found as a dimming control. Disadvantage between this option and a slider or knob, is that it has a fixed speed of change. Also, without a descriptive label it might not be intuitive, and it is challenging to simply convey such secondary actuations in simple graphics.

- Visual feedback - analog systems can interact back with the user through indicator lights showing the operational status of the system/light source. Here the usual colours associated with working/nonworking conditions are commonly used - green for working, red for non-working. Other colours, and dynamics (i.eg. blinking can also be used), though they usually require additional explanatory information as they can be interpreted in many ways. Basic standard meanings of colors for any interface is specified in an international standard.

- $\quad$ Tactile Feedback - through physical interaction, analog systems offer instant tactile feedback (change of physical status of the device, (.eg. pressed button, moved position of the toggle etc.)

\subsection{Digital Lighting User Interfaces}

Digital UI were a successor of analog systems and gained popularity on the market with the development of cheap, versatile screens and two-way communication between luminaries and the controls. At their core, the digital UI are mimicking the analog system with the difference, that the functions are activated on a screen, with a touch or slide of finger (or audio control in more advanced systems) on graphical elements, symbolizing the buttons, sliders, and other controls.

\footnotetext{
1 (Images sources:

https://socketstore.co.uk/products/sockets-and-switches/white/retrotouch-white/retrotouch-simplicity-white-intermediate-light-switch-1-gang https://www.amazon.in/SpeedFreakCNC-Toggle-Child-Safe-Residential-Lighting/dp/B06XC44D9H

https://www.ukelectricalsupplies.com/lutron-lyneo-preset-slide-dimmer-with-status-light.htm

https://www.homedepot.com/p/Lutron-Skylark-Contour-Slide-LED-Dimmer-Switch-for-Dimmable-LED-Incandescent-Halogen-Bulbs-Single-Pole-wWallplate-White-CTCL-WHW/302588468 
Advantage of the digital $\mathrm{UI}$ is that it is very easily changeable through updates (installed by a technician, or by the user if downloaded via internet). Such updates can modify the graphical layout, optimize the code, add features and so on, while the user does not need to purchase any additional equipment. This strategy also increases the feedback loop between the users and manufacturers.

Moreover, digital UI removes the risks of non-intuitive icon systems, by having a possibility of adding optional descriptive text for each option - in any chosen language. From a user point of view this is a great asset, especially while dealing with more complex control systems.

Another asset of digital UI is the use of two-way communication data available to the user. Not only can one control the light, but also can access database of scenes, daily light usage, energy consumption over time etc. Screen-based digital interface can also give a visual feedback of any function and important messages, for example about errors, need of maintenance works, updates and others.

With screen-based digital UI comes also the ease of realizing multi-platform with unified design. One system can be operated on an in-house tablet controlling all the lights, smartphone app or a laptop. All of this by multiple users of the space, e.g. household inhabitants.

In terms of difficulty of the setup, digital UI are harder to initially "install" by the user as they require a number of steps. However after the first use, they become secure and easy to handle. Initial setup steps usually require some physical input, such as pressing physical buttons on so called "gateways", in order to make the system secure and hack-proof - no new device can be connected to the system without pressing a physical button upon the first wireless pairing.

For the location of the digital controls, beside the portable controls in form of an app on tablet or smartphone, a wall-mounted control panel (screen) is usually placed close to the entrance of a space. In case of combined systems (.2.3.), an ergonomic solution is to have a digital control unit somewhere in center of the house, where it is easily and fast accessible, and combine it with manual switches connected with the system, e.g. at the entrance to the house or other buildings.
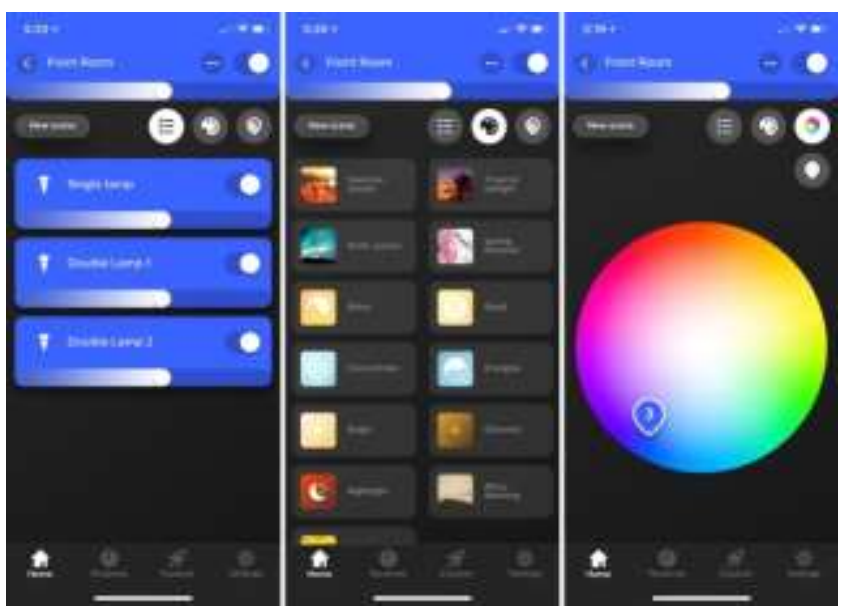

Figure 2. Example of UI: Phillips Hue App interface - from left: 1) different light sources with their intensity shown by slider, and currently set colour 2) Selection of lighting scenes 3) A colour control over lighting in selected room "Front Room".'2

\footnotetext{
2 (Image source: https://graduation.emilflach.com/light/)
} 


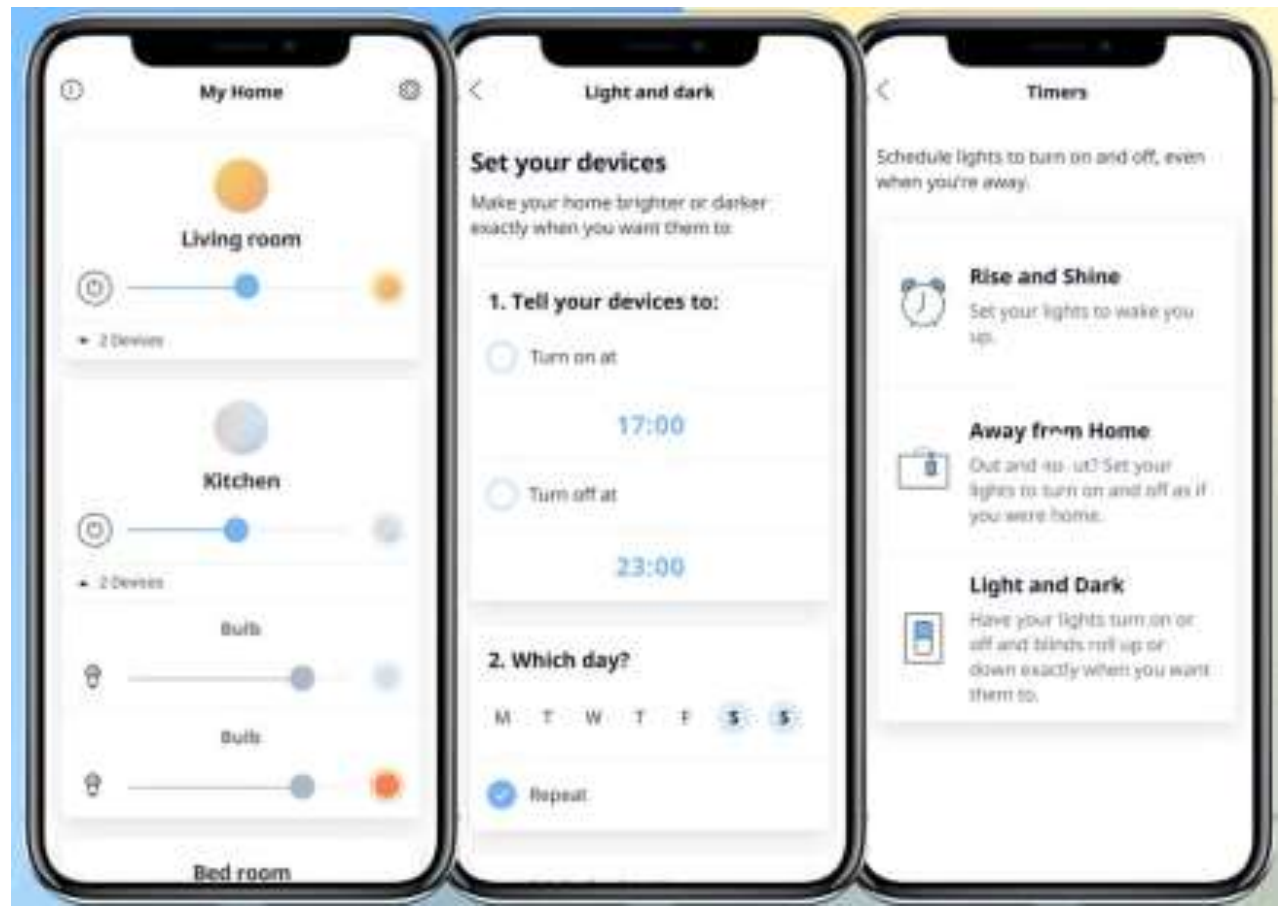

Figure 3. Example of UI: Ikea Smart Home App interface - from left: 1) Dimming of rooms and specific light sources. 2) Setting dynamic control using clock and calendar. 3) Setting dynamic control over lighting by defining scenes. ${ }^{3}$

\section{Functionality - types of interaction}

Essentially, the digital UI has all the options associated with touch screen, as well as numerous feedback options provided by the controlling device and two-way communication with the system and output devices:

- $\quad$ Touch screen control: Pressing, tapping (or double, triple tapping etc.), holding pressed button, sliding, rotating a digital knob/wheel. Essentially - any touch based interaction can be programmed.

- Visual feedback - system interacts with user showing visual communicates.

- $\quad$ Audio feedback - triggering audio feedback in forms of short sounds or communicates.

- $\quad$ Tactile feedback - as limited as it is, some touch screens offer tactile feedback in forms of gentle vibrations of the screen indicating receiving the signal.

\subsection{Combined / hybrid systems}

Many of the modern systems combine the two categories, by offering systems that operate on both digital apps (tablet, smartphone), as well as through remote controllers. An example of this type of system is IKEA Tradfri, or Phillips HUE.

In such systems, users who do not wish to open up a tablet and choose from the screen, can pre-program settings to physical remote-controls with buttons/sliders or other physical control elements, and simply initiate them up from there.

Continuing with Phillips and IKEA examples, below are the analog control devices that work together within same systems with the digital interfaces shown in the section above, e.g. Wi-Fi or Zigbee networks.

\footnotetext{
3 (Image source: https://www.fastcompany.com/90374061/ikea-doubles-down-on-smart-homes )
} 

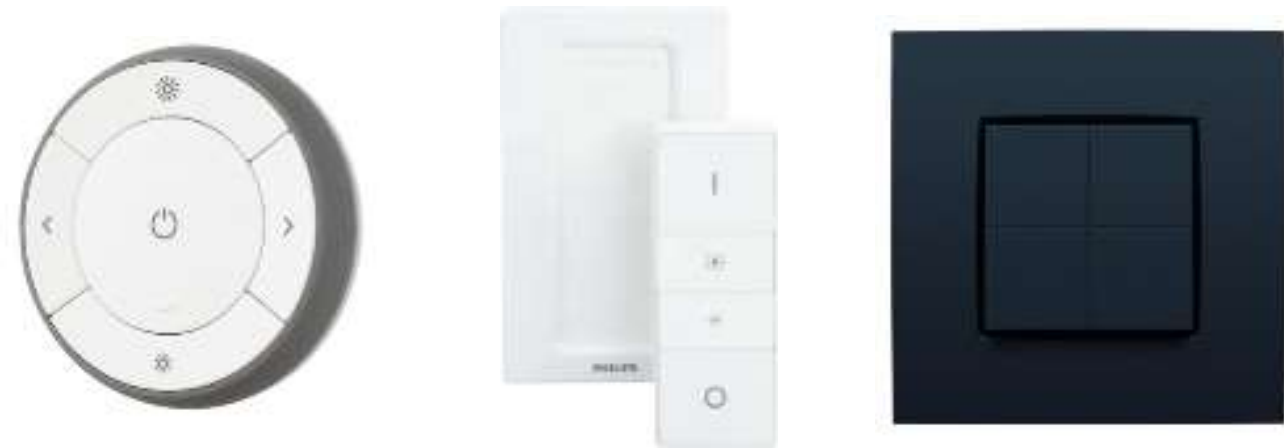

Figure 4. Examples of wireless analog controllers that are connected to the combined network. From left: IKEA TRADFRI remote, Phillips HUE On/Off/Scene select remote with dimmer, Phillips Smart Button with 4 programmable buttons. $^{4}$

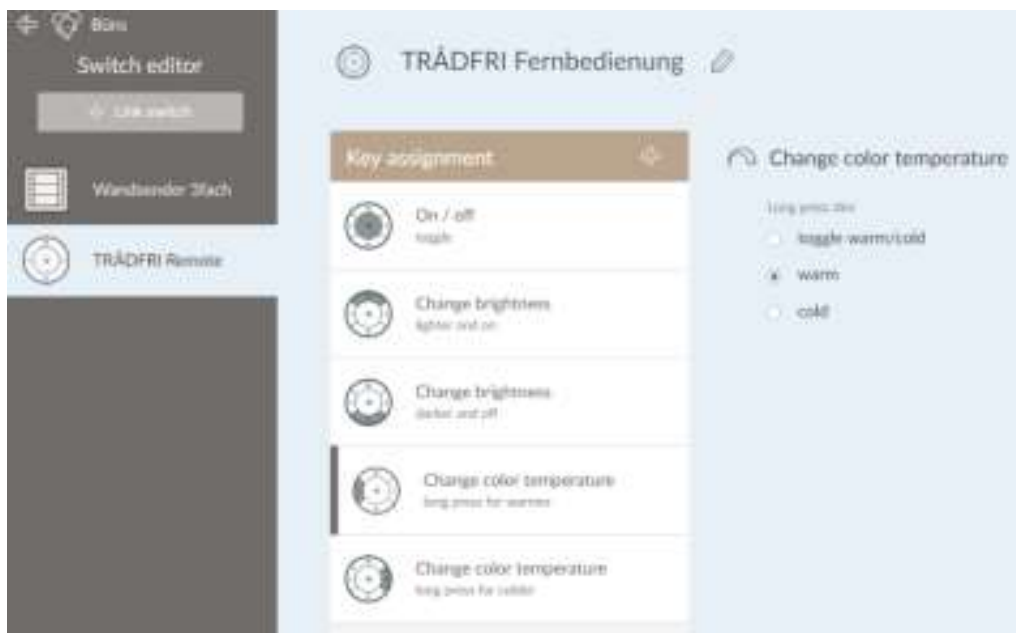

Figure 5. Examples of mapping buttons of the IKEA TRADFRI remote system. ${ }^{5}$

\footnotetext{
4 (Images sources:

https://www.ikea.com/gb/en/p/tradfri-remote-control-30443124/

https://www.conrad.com/p/philips-lighting-hue-remote-control-dimmer-switch-1588619)

5 (Image source:

https://github.com/dresden-elektronik/phoscon-app-beta/issues/176)
}

\section{Page 13}




\section{Functionalities}

User interface generally consists of controls over one or more of the parameters specified below:

\subsection{On Off - basic function, self-explanatory}

Usually represented by worldwide-recognized symbols for power on/off (as in example below - with reference to relevant IEC5007-10/IEEE 1621), or text "ON"' and "OFF", sometimes also with light bulb with, and without rays symbolizing emitting light

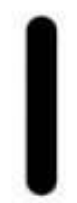

IEC 5007

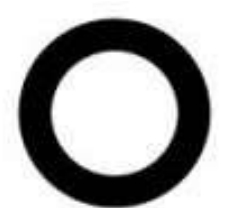

IEC 5008

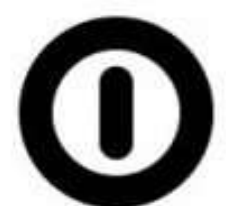

IEC 5010

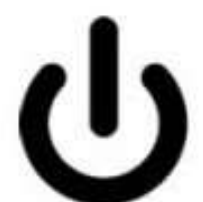

IEC 5009

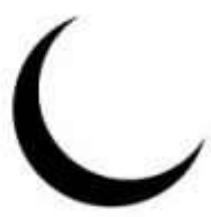

IEEE 1621

Figure 6. Examples of Power, Standby and Sleep symbols and relevant sources. ${ }^{6}$

\subsection{Dimming}

Dimming - traditional linear control function adjusting lumen output of the light source. It is usually controlled by $\mathrm{knob} / \mathrm{slider}$ in analog systems, and their visual representation on digital displays. Other used control mechanisms are buttons where it is possible to either hold and smoothly change the value, or press multiple times for step increase or decrease. If used, graphics are mostly: a line increasing in its weight that follows the slider/knob, a bulb or sun with small and bigger size or increasing size of the rays, plus and minus, up and down symbols, or descriptive text consisting of \% displayed in numbers. See examples below.

The proposed user interface standard uses Brightness as the fundamental concept to be conveyed, with Dimming as just a method to adjust the Brightness Level of a light source.
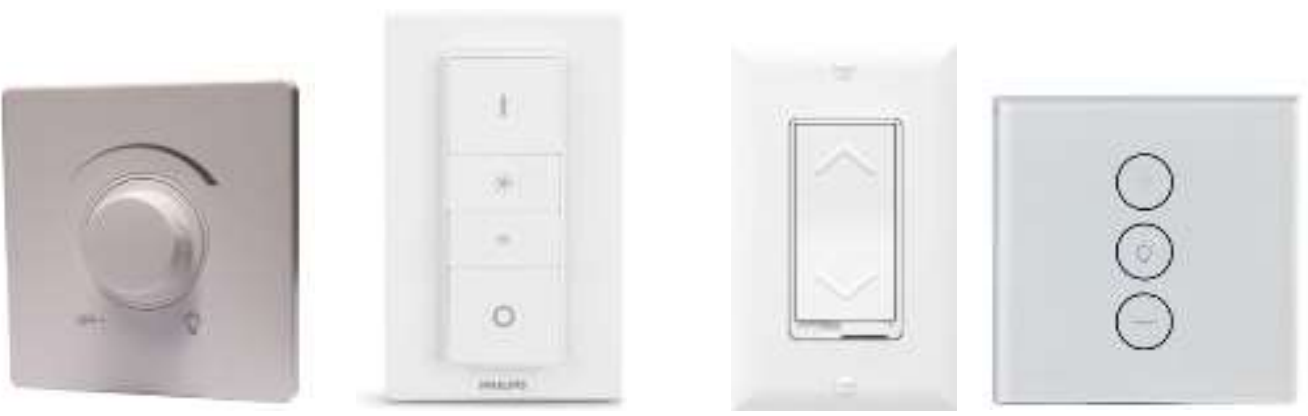

Figure 7. Examples of analog dimmers with different graphics visualizing controls.

\footnotetext{
6 (Image source:

https://99percentinvisible.org/article/modern-hieroglyphics-binary-logic-behind-universal-power-symbol/)
} 

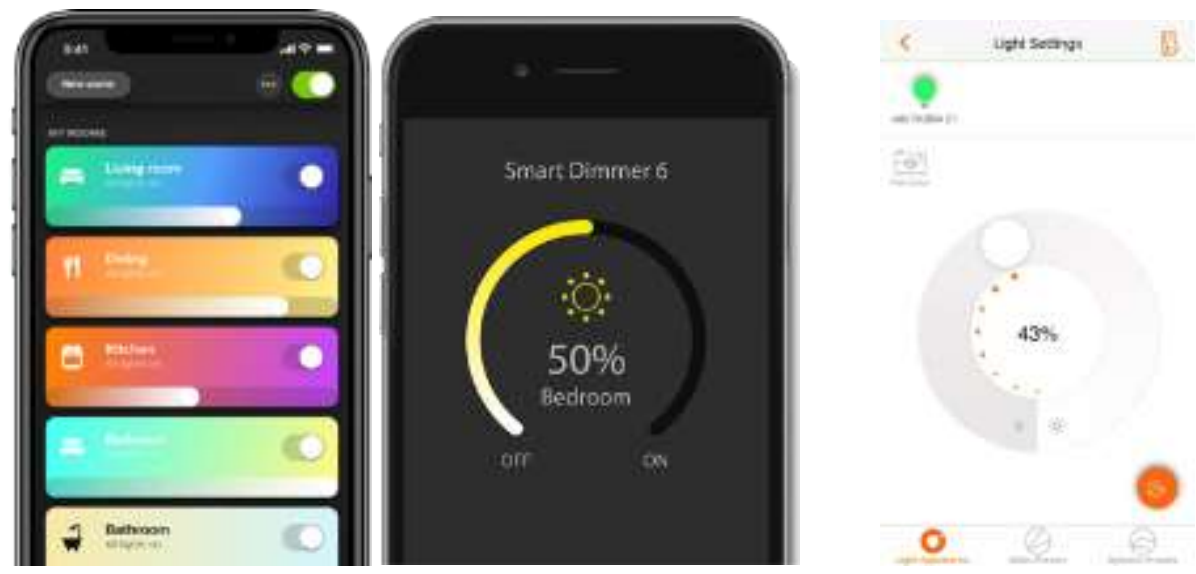

Figure 8. Dimming controls in User Interfaces from different lighting control systems. ${ }^{7}$

\subsection{Tunable White - controlling the Correlated Colour Temperature of lighting.}

Applicable with LED light sources. Usually manipulated with a slider, knob, or a colour wheel/circle. Here the manufacturers rather refrain from using any text, as this can be a confusing parameter: cool colour temperature is expressed in high numbers $(5000 \mathrm{~K}+$ ) while warm colour temperature in lower numbers (3000K and below). For everyday users warm temperature is usually associated with high temperature, hence the numbers do not make sense, and thus a colourful representation on $\mathrm{UI}$ is much more intuitive.

Tunable white raises a problem for user interfaces in that colour temperature is backwards from air and water temperature in that a higher value is cooler, not warmer. In the figure below, the first control has more (clockwise) being warmer while the third having more as cooler. The second one shows the absolute color temperature in Kelvin and so is using a rotary control consistent with that. The first matches people's experience of air and water temperature with more being warm. This is likely an unsolvable problem without abandoning literal color "temperature" as the fundamental concept that the UI elements are derived from; a different metaphor consistent with user expectations could solve this, as in the proposed UI standard content.
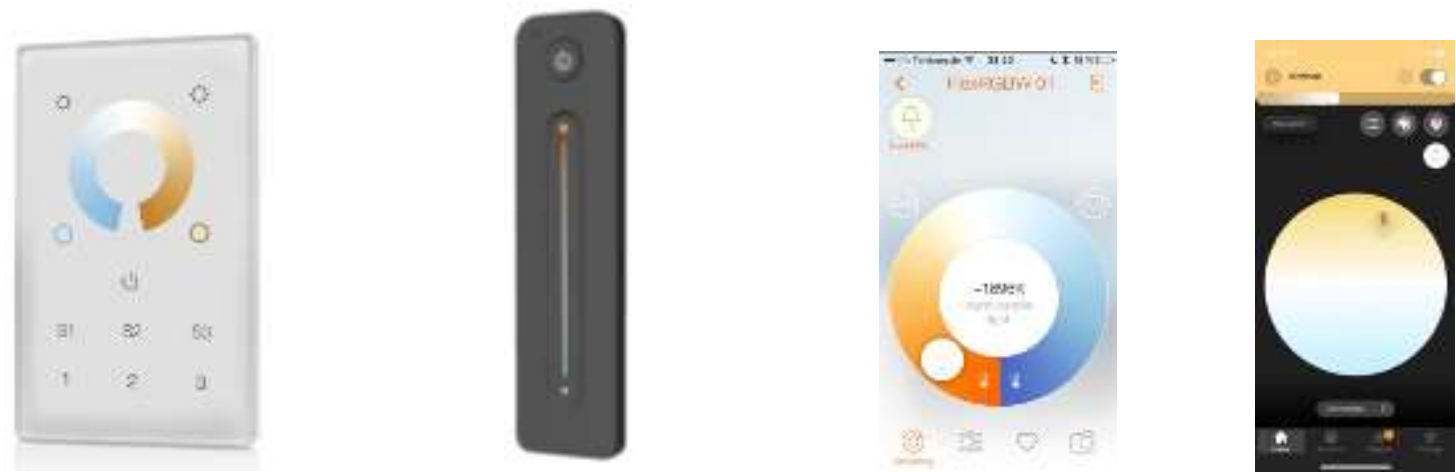

Figure 9. Two analog and two digital user interfaces for CCT control of lighting. ${ }^{8}$

\footnotetext{
8 (Image sources:

https://cnzihaile.en.made-in-china.com/product/KyWQXjGTlqVN/China-Hailar-500W-Dimmer-Switch-Light-Dimmer.html https://energyefficientsmart.com/product/philips-hue-smart-dimmer-switch-with-remote-requires-hue-hub/ https://www.amazon.com/TOPGREENER-TGDS-120-Dimmable-Incandescent-Electrical/dp/B074GGSBHH https://www.aliexpress.com/item/32946757894.html https://www.philips-hue.com/en-us/get-started

https://www.aeotec.co.za/products/smart-dimmer-6

https://www.osram.com/cb/lightify/lightify-home/lightify-mobile-app/index.jsp) 9 (Image sources:

https://www.sunricher.com/3-groups-cct-zigbee-touch-remote-controller-sr-zg9001t3-cct-us.html https://www.ledspace.co.uk/products/single-zone-cct-bi-colour-dimmer-with-wall-holder https://tchgdns.de/osram-lightify-test PHILIPS HUE App Screenshot
} 


\subsection{Colour control}

Generally, the user controls the colour through a colour wheel, or buttons with pre-defined colour mixes. In addition, some systems offer numerical representation of intensity of each of the three channels: red, green, and blue, in order to be able to specifically recreate some colours. Colour control is an emerging area of lighting control; how this could be standardized in user interface elements is not yet clear. Note that in Figure 11, the colour palette shown in the last one is rotated and a mirror image of the second one. This is a minor example of the pointless inconsistency found in many lighting controls.
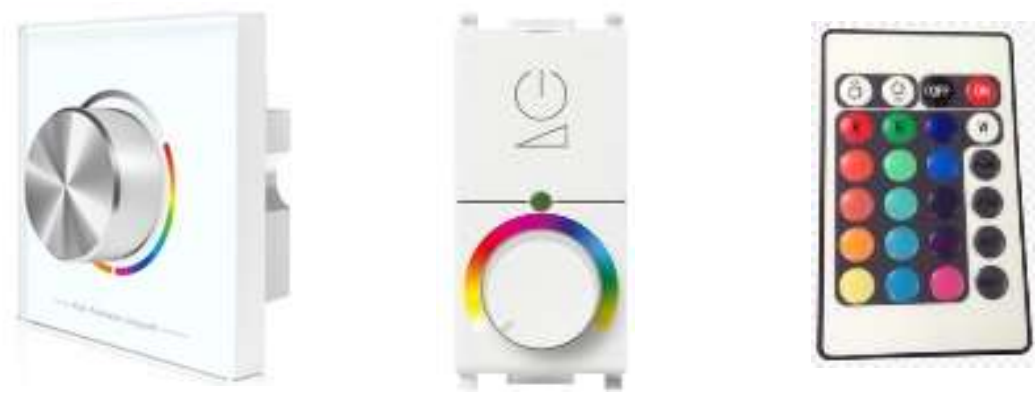

Figure 10. Two analog fixed controls (on the wall) and an infrared remote controller with colour assigned to buttons.
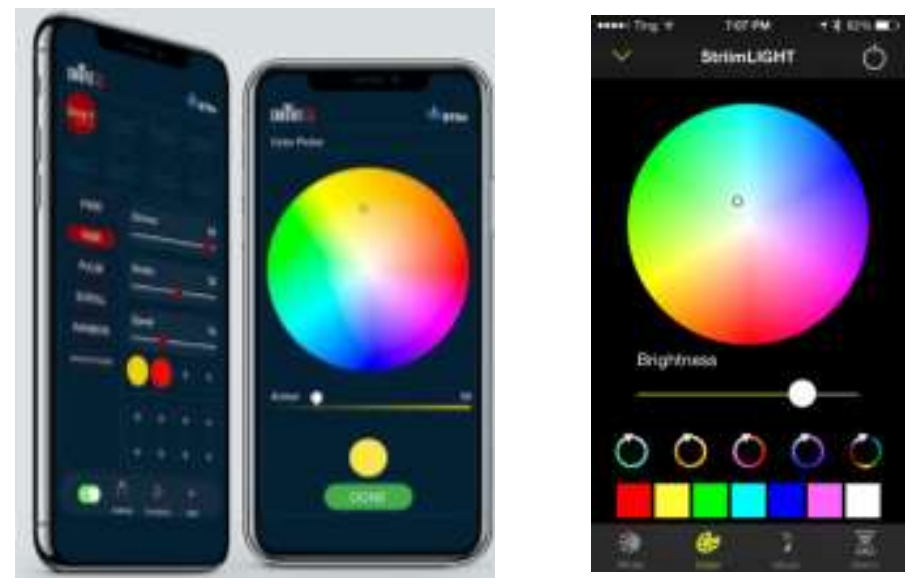

Figure 11. Examples of colour control in User Interface in different lighting control systems applications. ${ }^{9}$

\subsection{Dynamic controls}

Lighting can be programmed to actuate a based on sensor input. This option can be found as default in many offices or even residential buildings in common areas. It usually has an option to be overridden by the user. The signal can be sent based on:

- A schedule (calendar, hours) - where user specifies when does the light turn on and off, and other parameters if available. Usually used Icon is the clock. A good example of modern use of this parameter is with IKEA's "Rise and shine" program, where the lights slowly brighten starting 30 minutes before the user setting.

- Occupancy and presence - usually with passive infrared (PIR) sensors, most commonly represented by icon of a moving person, sometimes with a WI-FI waves above him representing the PIR sensor

- Daylight sensor - dimming (or turning on/off) of light sources synchronized with daylight intensity.

\footnotetext{
9 (Image sources:

http://www.ledilluminationlights.com/sale-10174904-rgb-cct-dim-led-light-controller-led-constant-voltage-2-in-1-controller-panel.html https://solis/ux.eu/en/products/sockets-and-switces-frames/vimar/plana/plana-devices/

https://www.bol.com/nl/p/ibiza-light-led-sphere20-20cm-led-pool-tuin-verlichting/9200000047813426/?country=BE

https://www.supremeaudio.com/chauvet-btair-lighting-control-app/

https://www.techhive.com/article/2984669/led-lights-that-play-music-great-idea-or-practical-joke-we-review-four-connected-q

lightingspeaker-co.html)
} 
This topic shows the need for a UI standard. While there are standard symbols for time during a day (a clock) and time across days (a calendar), there are no existing standard symbols for occupancy or daylight control. The proposed UI standard aims to fill this gap.
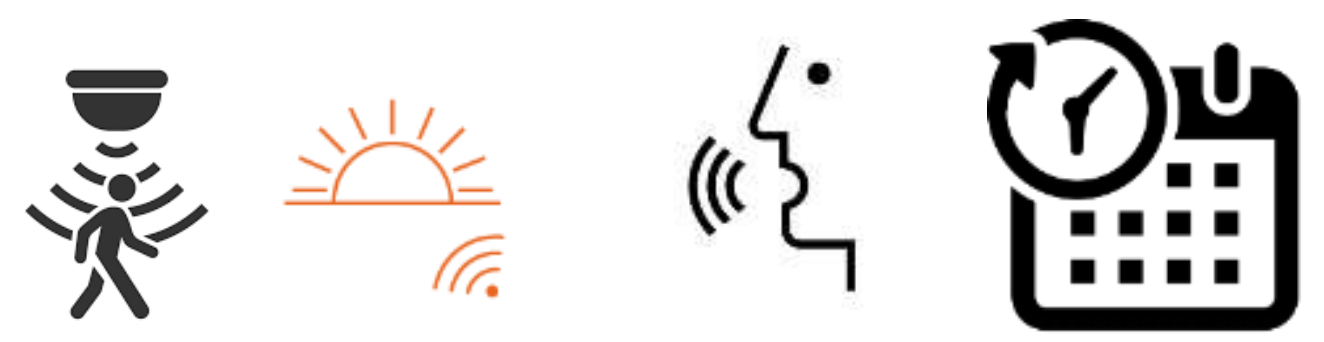

Figure 12. Examples of symbols in User Interface showing different sensors - occupancy, daylight, voice, calendar. ${ }^{10}$

\subsection{Scenes}

Scenes - as mentioned briefly above, modern systems also offer "lighting scenes", which are preprogrammed settings of one or more parameters described above, that can be called with a single click of a button or tap on the screen. Scene selection is made to save time and increase comfort of the user, especially if there is so many parameters to determine - in order to avoid doing it each time while turning on the lighting. For the professionals within industries relying on lighting (designers etc.) using lighting scenes (and saving them) is very beneficial as it secures that certain products are viewed in same light conditions. Furthermore, manufacturers start to propose pre-defined scenes to give ideas how to use their products and benefit from all the possible advantages. For example, increased comfort for activities requiring focus by using cool colour temperature and bright scenes, or an energy-saving scene which utilizes daylight sensor or clock for gradual dimming of lighting.
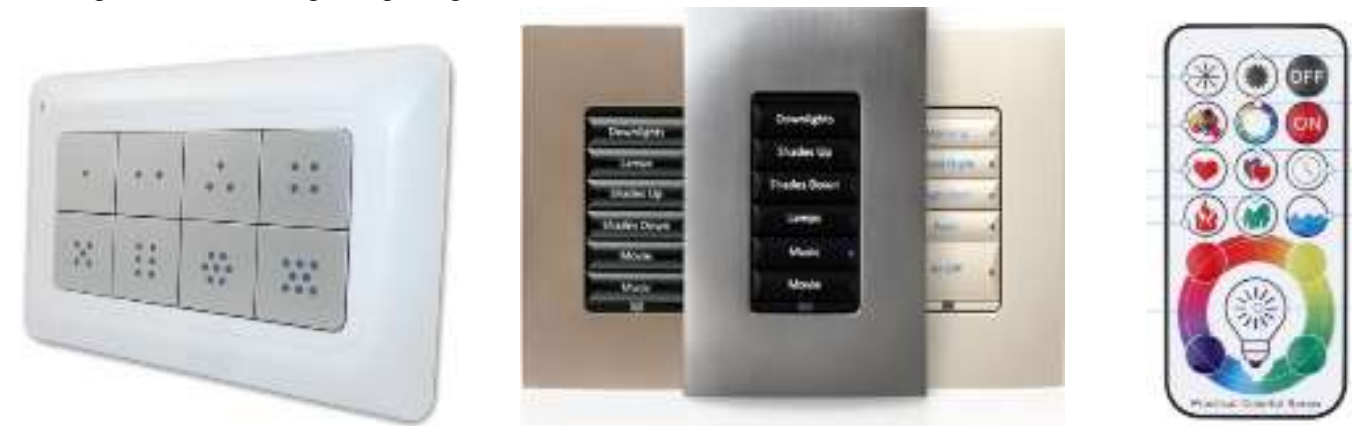

Figure 13. Examples of analog lighting scenes Ul controllers - two static, wall mounted, and an infrared remote (on the right).

\footnotetext{
10 Images sources:

https://www.lampshoponline.com/osram-11-5w-led-gls-motion-sensor-e27-2700k.html https://casambi.com/why-casambi/functionality

https://www.pngquru.com/free-transparent-background-png-clipart-whyad)
} 


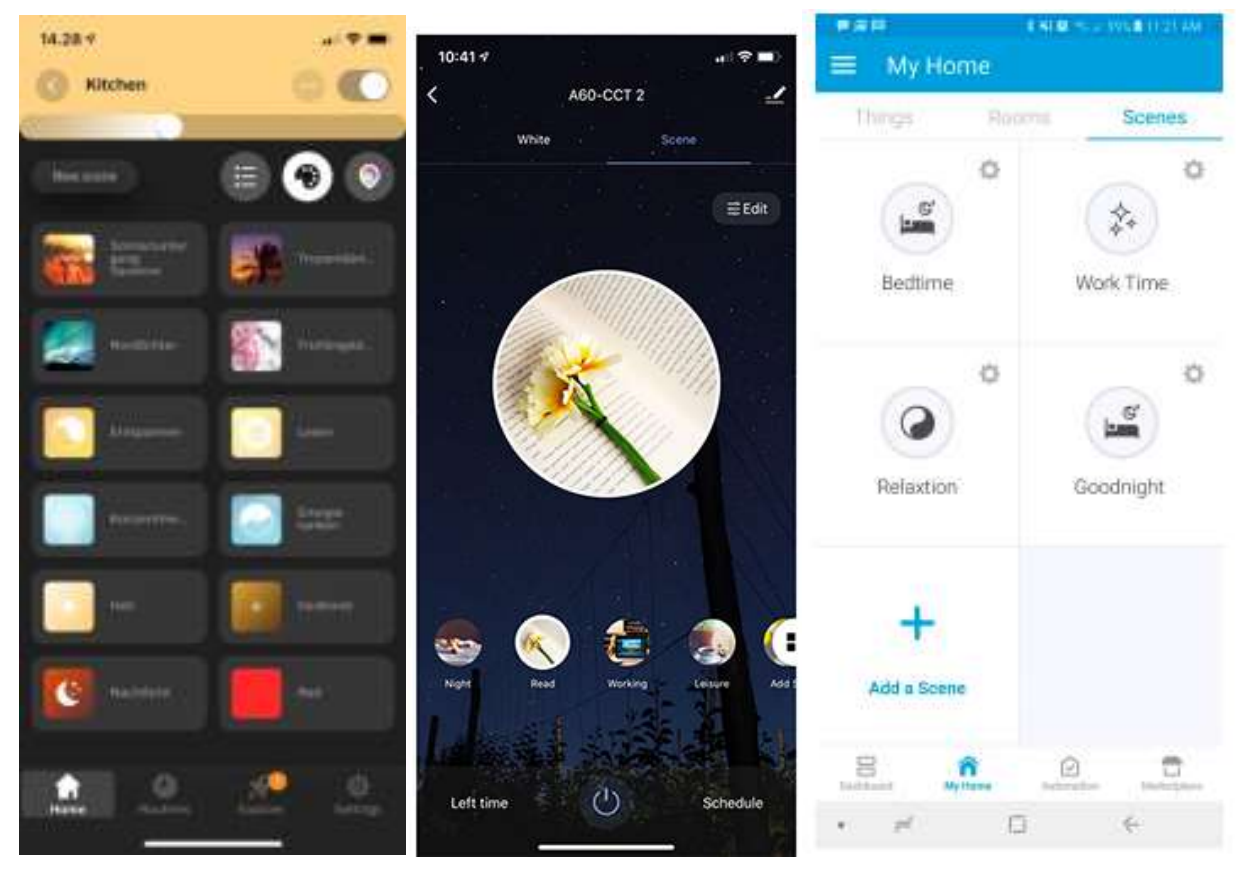

Figure 14. Examples of lighting scenes control in digital Ul's. ${ }^{11}$

\subsection{Interfaces for control of shades, blinds, curtains and shutters}

User Interfaces can also help can also have controls over shading system - e.g. tilt, up/down, close/open. Icons depend on the type of shades.

Here are the key functionalities:

- Offer possibility to occupants to react to intrusive sunlight, through reducing light in the room, glare, and heat penetration.

- Increase privacy through blocking the views in from the outside.

- Provide temporary low brightness atmosphere during video shows, conferences, and TV viewing.

Here are newer and more elaborated functionalities:

- Provide a network to allow one master switch to control zones or entire installation.

- Propose remote control from the internet (user acts remotely).

- Propose simple programmable solutions (clock based, or related to climatic conditions -wind -sun).

\footnotetext{
11 (Images sources:

https://www.amazon.co.uk/Remotec-scene-master-remote-z-wave/dp/B01DW10YW8
} 

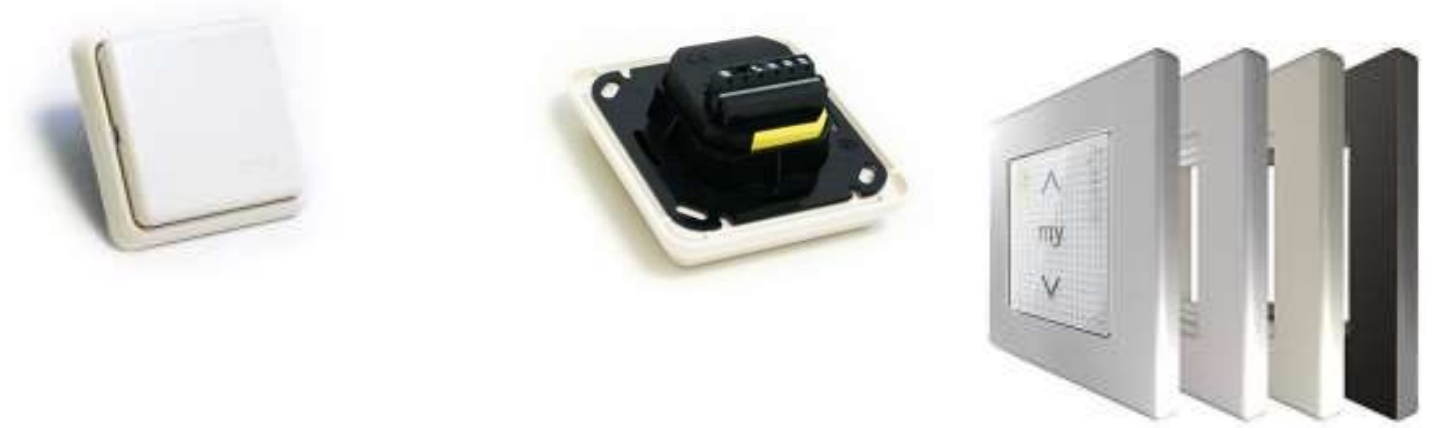

Figure 15. Example of shading switches dedicated to apertures, with possibility to have a master switch controlling the entire installation (open / close) Source SOMFY.
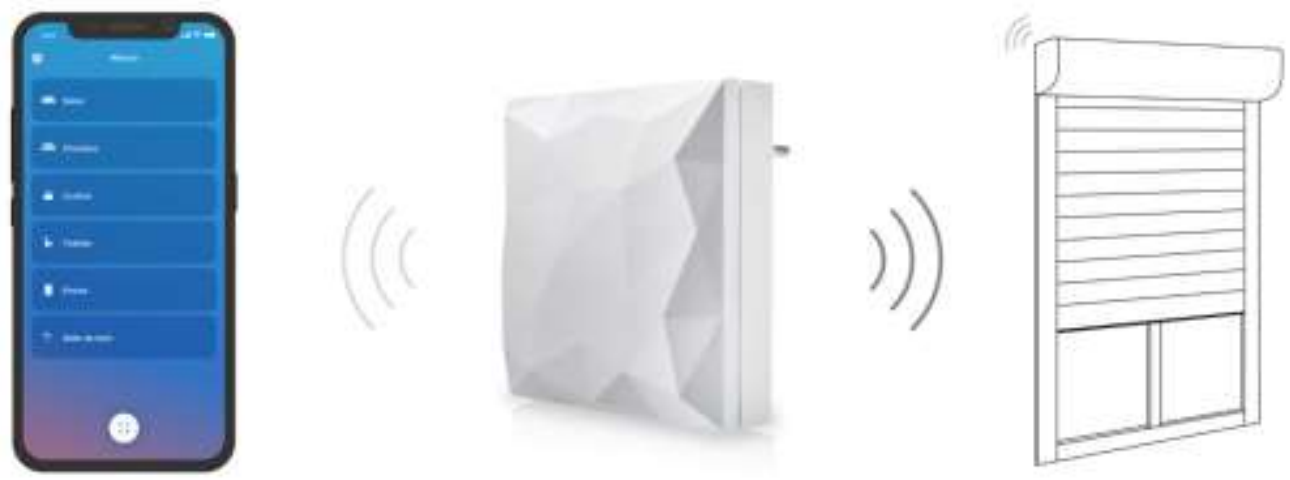

Figure 16. SmartPhone based interfaces by Bubendorff. 


\section{Telis Collection}
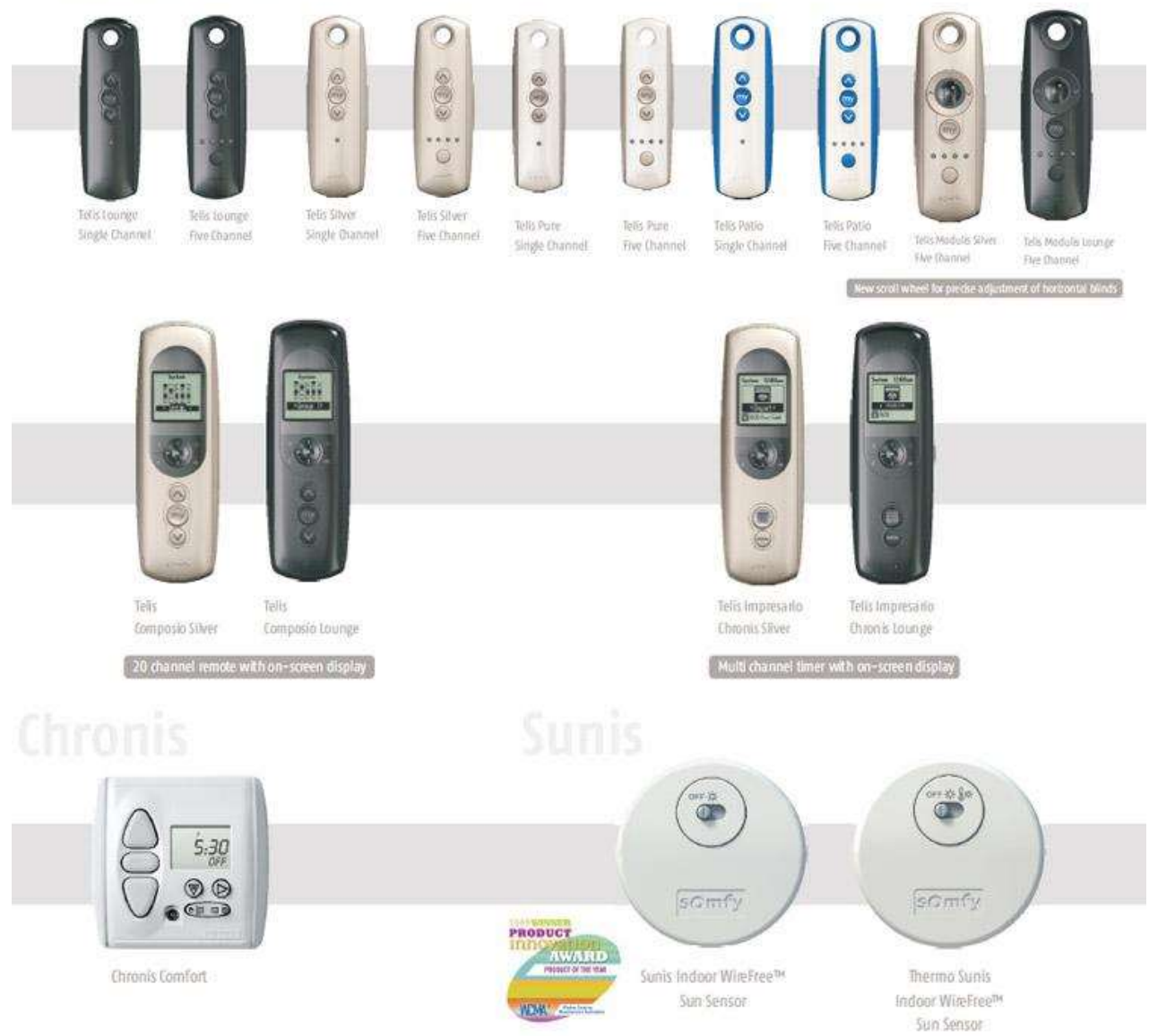

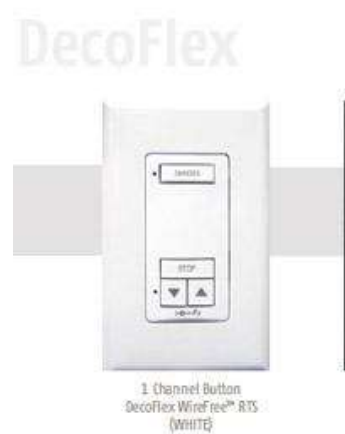

(vintite

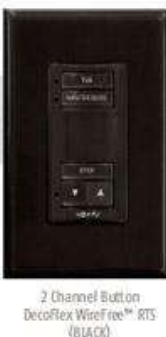

isucos

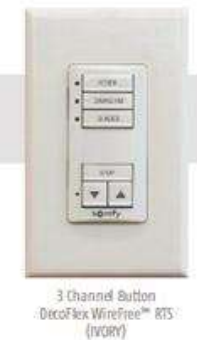

(Irophi)

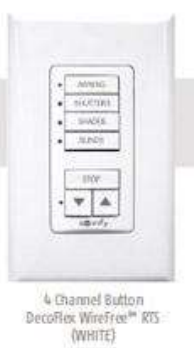

(WHitt)

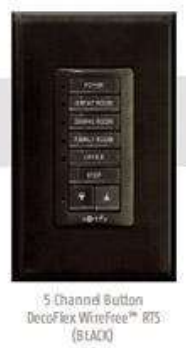

All Decoflex Wirefree ${ }^{M}$ RTS wall switches include mounting hardware for easy installation anywhere in the home. Printed Channel buttons are available to replace blank channel buttons or those with temporary stick on labels.

*All switches are available in 3 finishes

Figure 17. Large development of user interfaces for home shading systems. Wireless and wired interfaces by SOMFY.

\section{Potential of new generation user interfaces with shading systems}

In home automation, most system are independent. But the trend is to relate shading control to climatic conditions (to prevent overheating more particularly). The UI gives the possibility to both, program the control without PC, and to override the system.

In non-residential buildings, the user interface allow the occupants to override the automatic shading system, if there is one. 


\section{Trends for future}

Lighting Control User Interfaces are under significant development, and progressing both in quality and in functionality

- $\quad$ Remote control - data and control feed through the internet is becoming more and more popular option added to the user interface of lighting control systems. The system away from home, if it is connected to a router and internet - such options already exists as for example shown in fig X., with IKEA TRADFRI interface.

- Development by the users - In the digital era and accessibility to coding knowledge, many users decide to develop applications on their own. Such practice was noticed by manufacturers, for example Phillips, who made a special platform for such user-based development (https://developers.meethue.com). Such an online community exchanging apps and codes is an excellent source of ideas for further development of the official product. It can also show the versatility of the product in different settings and scenarios. In example browsing through user-developed apps one can find lighting control through hand gestures through infrared sensors, weather based light control (through online-received data), colour matching videos or other themes etc. For different application, users also develop their own interface systems, most efficient for the exact functionality that is needed.

- Personalization of the systems - on top of adjusting the lighting in forms of scenes, there also comes personalization of the UI itself. Digital displays offer options of changing the appearance of the device making it more fitting to the user, or designated space. On the other hand, manufacturers offer material selection for the finishes of the analog controls, which can amplify the character of the interior design of spaces.

- Synchronization with smart home systems - in the age of IOT with systems such as Amazon Alexa, Google Play Assistance or Apple HomeKit just to name a few, lighting is becoming an integrated element of Smart Home systems.

- $\quad$ Suggestive scenes from producers - to showcase the possibilities, and make it easy and readilyaccessible, producers pre-define numbers of scenes and make it accessible right after initializing the system. Some lighting scenes are marketed as "backed by research" - e.g. energizing light with peaks in blue spectrum, or on the other side of spectrum - evening light with reduced blue wavelengths for better sleep. In the future, we should expect more and more such solutions being available in the systems in forms of presets downloaded with updates.

- $\quad$ Shading control: interface are more user friendly and cost effective. They become gradually a standard, with motorized shading systems. They are significant elements to manage solar protection and shutters according to outdoor climatic conditions. Leading to benefits both in energy usage and comfort

As controls become more complex, the need for standardization of individual UI elements grows dramatically. In other domains, e.g. vehicles, telephony, media playback, we use international standard elements as a foundation for user comprehension. Such a standard is needed for lighting control. There are efforts underway to do this but require more attention from energy and lighting researchers, energy policy makers, the lighting control industry, and standards organizations.

One key trend of the future is to improve feedback to the system user, suggesting actions or informing on consequences of actions. 


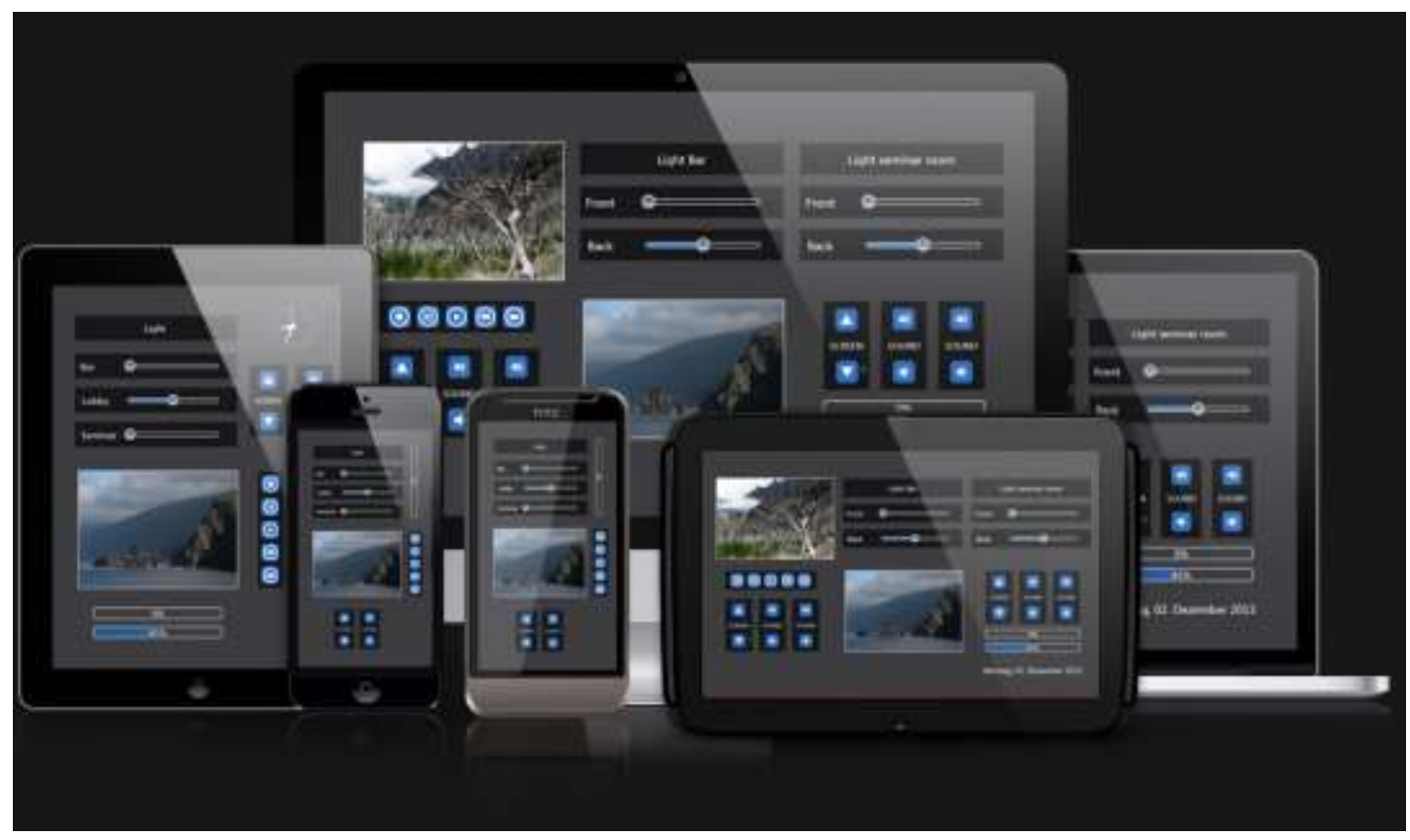

Figure 18. New generation of KNX interfaces.

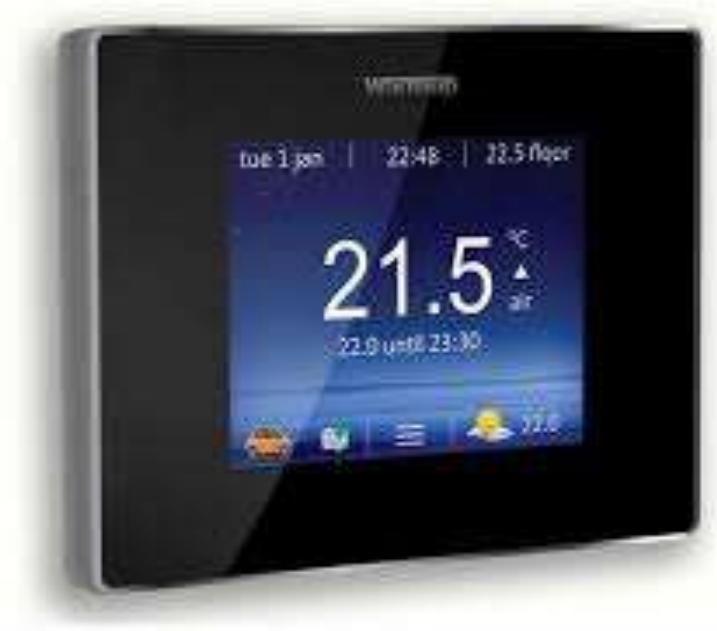

Figure 19. Interface by ONYX

\section{Conclusion: Energy saving and Lighting User Interfaces}

In terms of energy saving, a good UI makes all the difference for the user, and possibly for the management of energy flows.

The system's User Interface (UI) needs to be easy and intuitive, so the users actually know how, and want to use them. If the goal is to reduce energy use, e.g. through utilizing light scenes with intelligent sensor- and calendarbased dimming, they need to be presented to the user in an appealing, fun, and easily accessible way. Otherwise, many will just follow the principle "any light is better than no light" and do not think twice but just use a basic, easiest to access function of the system, which may be inefficient.

The new user interfaces make programming more simple and intuitive, and allow to avoid using traditional programming via PC. 
Interfaces on Smartphones are powerful and grid connected, allowing remote control through the web.

The energy management can be hidden and imbedded. It is a key element to train the user in optimizing the system, possibly in an attractive way. Understanding of the operation will allow the occupant to understand ways to reduce the energy consumption of his/her dwelling.

Price reduction will lead to harmonization between professionals and consumer products, both based on smartphone / tablet technologies.

Essential to user comprehension is broad consistency across controls, and user interface standards is the way this is accomplished. UI standards are essentially a dictionary of individual elements, for manufacturers to then assemble in ways that they see as appropriate. Without a basic dictionary to draw on, user comprehension is extremely difficult as systems become more complex.

\section{References}

Nordman, B., Dulla, S., Kloss, M., (2017,02,10). User Interface Product Survey Report, California Energy Commission Award No. EPC-14-017, Retrieved from https://drive.google.com/file/d/0B8B9XW6B7prIRUJ5QmdHNURDUTA/view

\section{Figures:}

Figure 1. Examples of analog User Interface control devices.

Figure 2. Example of UI: Phillips Hue App interface - from left: 1) different light sources with their intensity shown by slider, and currently set colour 2) Selection of lighting scenes 3) A colour control over lighting in selected room "Front Room".

Figure 3. Example of UI: Ikea Smart Home App interface - from left: 1) Dimming of rooms and specific light sources. 2) Setting dynamic control using clock and calendar. 3) Setting dynamic control over lighting by defining scenes.

Figure 4. Examples of wireless analog controllers that are connected to the combined network. From left: IKEA TRADFRI remote, Phillips HUE On/Off/Scene select remote with dimmer, Phillips Smart Button with 4 programmable buttons

Figure 5. Examples of mapping buttons of the IKEA TRADFRI remote system. ........................................... 13

Figure 6. Examples of Power symbols and relevant sources. ................................................................ 14

Figure 7. Examples of analog dimmers with different graphics visualizing controls....................................... 14

Figure 8. Dimming controls in User Interfaces from different lighting control systems................................... 15

Figure 9. Two analog and two digital user interfaces for CCT control of lighting. ......................................... 15

Figure 10. Two analog fixed controls (on the wall) and an infrared remote controller with colours assigned to

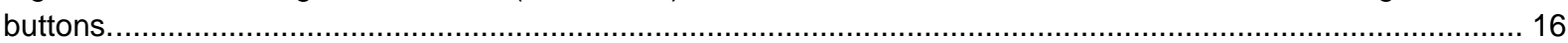

Figure 11. Examples of colour control in User Interface in different lighting control systems applications. .......... 16

Figure 12. Examples of symbols in User Interface showing different sensors - occupancy, daylight, voice,

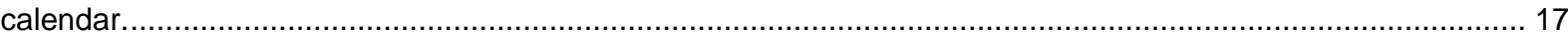

Figure 13. Examples of analog lighting scenes UI controllers - two static, wall mounted, and an infrared remote

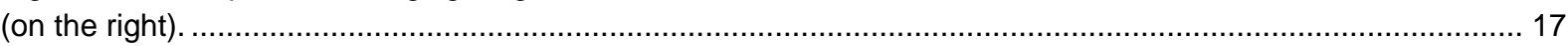

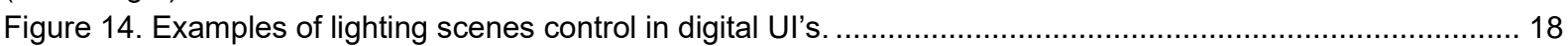

Figure 15. Example of shading swiches dedicated to apertures, with possibility to have a Masterswitch contolling the entire installation ( open / close) Source SOMFY............................................................................. 19

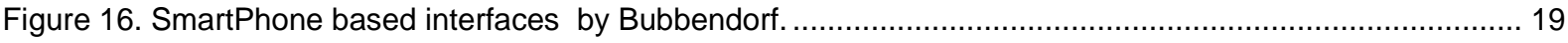

Figure 17. Large development of user interfaces for home shading systems. Wireless and wired interfaces by

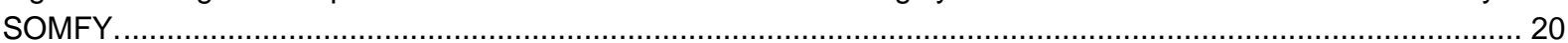

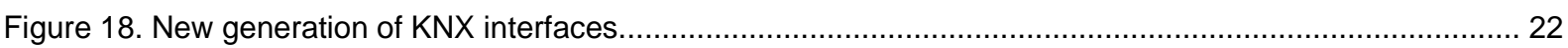

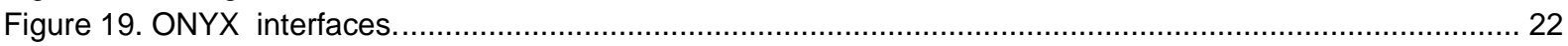

